\title{
ANÁLISE DE CUSTOS E MARGENS CONTRIBUTIVAS PARA TOMADA DE DECISÃO: UM ESTUDO DE CASO NA BARBEARIA TOC MÁGICO NO MUNICÍPIO DE CAPANEMA-PA
}

\section{ARTIGO ORIGINAL}

GOMES, Odon Praia ${ }^{1}$

BARROS, Rogelio Ruan Souza De ${ }^{2}$

Ó, Marco Aurelio Alves Leal do ${ }^{3}$

ARAÚJO, Jamille Carla Oliveira ${ }^{4}$

GOMES, Odon Praia. Análise de custos e margens contributivas para tomada de decisão: Um estudo de caso na barbearia Toc Mágico no Município de Capanema-PA. Revista Científica Multidisciplinar Núcleo do Conhecimento. Ano 04, Ed. 10, Vol. 07, pp. 30-55. Outubro de 2019. ISSN: 2448-0959, Link de acesso: https://www.nucleodoconhecimento.com.br/contabilidade/custos-e-margens

\section{RESUMO}

O presente trabalho tem como objetivo de demonstrar como a as análises de custos e margens contributivas podem ser utilizadas no auxílio do processo de tomadas decisão de um microempreendedor individual no município de Capanema, Pa. A

1 Discente do curso de Ciências Contábeis da Universidade Federal Rural da Amazônia (UFRA).

2 Discente do curso de Ciências Contábeis da Universidade Federal Rural da Amazônia (UFRA).

3 Doutorando em ciências Contábeis FUCAPE, Mestre em Administração, MBA Gestão contábil, perícia, auditoria e controlaria, Bacharel em Ciências Contábeis.

4 Mestre em Administração, MBA Gestão contábil, perícia, auditoria e controlaria, Bacharel em Ciências Contábeis. 
orientação teórico-metodológica utilizada, seguiu as concepções de Martins (2003), Proença \& Santos (2012) e Gil (2002), que abordam sobre a contabilidade de custos, margens contributivas e o procedimento técnicos para a pesquisa quantitativa. $O$ corpus do trabalho foi um estudo de caso na "barbearia "toc mágico" onde buscou-se através do cálculo das margens contributivas obter informações sobre a rentabilidade da referida. A pesquisa focou no levantamento dos custos fixos e variáveis da microempresa, o que possibilitou calcular sua margem de contribuição, ponto de equilíbrio, margem de segurança, bem como, sua lucratividade total. Neste contexto foi possível auxiliar o microempreendedor desse segmento no município, evidenciando quais os serviços mais rentáveis da barbearia estudada.

Palavras chaves: Margens contributivas, análises de custos, microempreendedor individual.

\section{INTRODUÇÃO}

De acordo com Martins (2003), a contabilidade de custos é uma ferramenta que além de visar o controle e as decisões gerenciais, torna-se essencial para os empreendedores conhecerem sua lucratividade e estabelecerem a segurança e o equilíbrio da empresa perante a competitividade e exigências do mercado.

Os estudo de custos e margem contributiva em uma barbearia no município de Capanema-Pará. Para isto, utilizou-se os fundamentos do método de custeio variável, pois são mais apropriados para este modelo de empresa, visto que, influenciam diretamente nas tomadas de decisões e são capazes de proporcionar informações mais completas sobre o seu desempenho financeiro, bem como, permitir observar os resultados do negócio. (PROENÇA \& SANTOS, 2012).

A pesquisa é um estudo de caso feito em uma barbearia, localizada no município de Capanema-Pará. O objetivo de demonstrar como a as análises de custos e margens contributivas podem ser utilizadas no auxílio do processo de tomadas decisão de um microempreendedor individual no município de Capanema, Pa. Para isto, foi necessário informar ao microempreendedor a importância dos conhecimentos básicos 
sobre métodos de custos e margens contributivas auxiliando na elaboração do preço final.

A princípio será abordado sobre contabilidade de custos, visto sua importância como recurso gerencial, bem como, os principais métodos de custeio e suas respectivas fórmulas. Para isto, utilizou-se renomados autores que tratam das concepções a respeito dos métodos de custeio como: Martins (2003), Proença e Santos (2014), Leone (1997), entre outros.

Em seguida apresenta-se as metodologias utilizadas para compor a pesquisa. Nela, definiu-se os aspectos e introduziu-se dados da pesquisa. Assim, foi possível definir um estudo de caso nesse segmento através de um MEI parceiro.

Para finalizar apresenta-se os cálculos dos custos fixos e variáveis da referida barbearia, visando obter o cálculo das margens contributivas, como: a margem de contribuição, o ponto de equilíbrio e a margem de segurança dos serviços ofertados, assim, foi possível prover o MEI com informações importantes sobre o desempenho e a lucratividade da sua microempresa.

Os homens estão na mira dos empreendedores do setor de beleza que é um ramo de atuação que vem crescendo consideravelmente, no município de Capanema Pará. Isso se deve ao fato de que os homens capanemenses estão cada vez mais vaidosos e preocupados com sua imagem pessoal, e este é um segmento que cresce em todo o Brasil. Um dos principais influenciadores para esse crescimento constante é uma cultura cada vez mais voltada ao cuidado com a saúde e o bem-estar, e a participação do homem no consumo de produtos e serviços vem se intensificando cada vez mais.

Diante do exposto, o referido trabalho, visa neste estudo de caso, apresentar todos os custos atribuídos a prestação dos serviços da barbearia estudada, bem como, a aplicação das margens contributivas, auxiliando no processo da tomada de decisão à curto prazo da referida Microempresa. 


\section{REFERENCIAL TEÓRICO}

\section{CONTABILIDADE DE CUSTOS COMO FERRAMENTA DE TOMADA DE DECISÃO}

A contabilidade de custos no início estava voltada para obtenção de informações que permitissem um maior controle de estoque e de resultados alcançados. Mas, ao longo dos anos, percebeu-se que a contabilidade de custos gerava dados mais completos capazes de influenciar nas tomadas de decisões.(PROENÇA E SANTOS, 2014).

Para Martins (2003, p.15) a "a Contabilidade de Custos acabou por passar, nessas últimas décadas, de mera auxiliar na avaliação de estoques e lucros globais para importante arma de controle e decisões gerenciais." Assim o autor destaca a importância da contabilidade de custos não apenas para fazer a mensuração de produtos ou serviços, mas como também uma ferramenta em potencial que permite 0 conhecimento da lucratividade, proporcionando margens de segurança e até sobrevivência das empresas no mercado. Para isso, é necessário ter notórios conhecimentos sobre cada método de custeio.

\section{MÉTODOS DE CUSTEIO}

Segundo Leone e Leone R. (2010, p.44) “...existem muitos tipos de custos que se destinam exclusivamente a compor informações gerenciais para o processo decisório." Por isto, tornar estes custos subjetivos em valores visíveis tem facilitado as tomadas de decisões.

Os métodos de custeio têm como objetivo acumular e apurar custos, e os métodos mais utilizados são: o de custeio variável e o de absorção. Ambos operam com suas particularidades para a acumulação de custos, no entanto, são métodos distintos. (CREPALDI, 2016). Nesse sentido, o autor afirma que estes se dividem entre dos tipos: custos diretos e indiretos. Os custos diretos são gastos diretamente ligados aos produtos, e se alteram conforme a quantidade da produção. Basicamente, são os custos diretos com material ou mão de obra para produzir determinado produto. 
Toma-se como exemplos, os custos com matéria-prima; material secundário e embalagens. No entanto, os custos indiretos são os gastos vinculados ao processo de produção e não diretamente aos produtos. Como não são identificados diretamente, para serem calculados, é preciso utilizar técnicas de rateio, um tipo de instrumento que faz a distribuição e a divisão dos custos indiretos. A exemplos, pode se citar a conta de energia consumida, custos com manutenções de máquinas etc. (CREPALDI 2016).

\section{CUSTEIO POR ABSORÇÃO}

É conhecida como uma metodologia baseada nos princípios da contabilidade. É utilizado para levantar todos os custos envolvidos durante o processo de produção em um determinado período. Assim, estes custos (gastos) devem ser lançados para todos os produtos ou serviços produzidos. (MARTINS, 2003).

Para Crepaldi (2016, p. 229) neste tipo de método, “...os custos de produção podem ser apropriados diretamente, como é o caso do material direto e mão de obra direta, ou indiretamente, como é o caso dos custos indiretos de fabricação". Sendo assim, todos os gastos que pertencerem ao processo produtivo, entrará no cálculo desse método, até mesmo, os gastos fixos e variáveis.

Por isso, tal método não é indicado para tomadas de decisão, visto que, não são calculados outros gastos importantes não pertencentes ao de produção.(PROENÇA E SANTOS, 2014)

Assim, evidencia-se que o método de absorção é uma metodologia mais abrangente, focada no processo produtivo como um todo, e que por isso, não se obtém um retorno rápido das informações dos custos, não sendo muito apropriado para as tomadas de decisão à curto prazo.

\section{$\mathrm{ABC}$}

O método ABC - Custeamento Baseado em Atividades - surgiu de um contexto de avançados progressos das tecnologias de comunicação e informação, exigindo assim, 
maior competitividade entre as empresas, que para se manterem ativas, buscaram oferecer produtos ou serviços de qualidade, mas com pouco custo. O método funciona apropriando e atribuindo os gastos de todas as atividades consumidas para se obter os produtos. Por isso, seu principal foco está em custos indiretos, sendo assim, oferece um maior controle dos gastos e pode ser um diferencial para as tomadas decisões. (LEONE E LEONE, 2010).

Para Martins (2010), "com base no ABC tem-se a possibilidade de uma alocação mais racional de muitos custos e despesas a todos os produtos". Segundo o estudioso, tal método é muito utilizado com o objetivo de se obter os gastos e despesas de um produto de modo mais amplo, acrescentando apenas o lucro desejado por unidade, o que facilita estabelecer um preço para a venda.

No entanto, o $A B C$ apresenta alguns entraves para tomadas de decisões à curto prazo, pois como o método se utiliza dos conceitos da absorção, que trabalha de forma mais ampla, há uma certa dificuldade em se estabelecer análises mais rápidas. Além disso, o ABC exige maior atenção durante as análises dos custos, visto que, tende a modificar os custos fixos em variáveis. (LEONE E LEONE, 2010).

Portanto, o $A B C$ apesar de ser um método que trabalha mais com os custos variáveis por unidade produzida, não é muito apropriado para estabelecer as tomadas de decisões à curto prazo, visto que, seus resultados são mais lógicos e completos, e por isso, acabam demorando mais para serem obtidos.

\section{CUSTEIO RKW}

O RKW - Reichskuratorium Fur Wirtschaftlichtkeit- surgiu no século XX como uma técnica alemã para fixar os preços a partir dos custos. O RKW processa todos os custos com a produção, bem como, todas as despesas da empresa. Para isso, faz o rateio completo de todo o processo empresarial, tornando-se assim, um método mais complexo, que demanda de uma melhor centralização e precisão da economia, o que não o torna muito apropriado para trabalhar junto ao mercado, visto que, este está em constante variação devido o mecanismo de oferta e procura. (Martins, 2010). 
Dessa forma, este método não é considerado um dos mais viáveis para as tomadas de decisões, visto que, também se baseia no método de absorção e acaba levantando todos os custos da produção, não considerando outros fatores, além de ser muito dependente do desempenho da economia.

\section{CUSTEIO VARIÁVEL OU DIRETO}

O custo variável ou direto é um método de custeio que opera somente com os gastos variáveis ocorridos em um determinado período, geralmente à curto prazo, durante 0 processo produtivo. Portanto, faz uso apenas de valores específicos, oscilantes e temporários. (CREPALDI, 2016).

Como o custeamento variável é centralizado em custos específicos, este método não é permitido pela legislação e órgãos competentes de fiscalização, pois no Brasil, o uso com base em método de absorção é obrigatório, visto que, fazem um apanhado geral dos custos das empresas. (LEONE E LEONE, 2010).

Para Martins (2010, p. 198) no custeamento variável, "só são alocados aos produtos os custos variáveis, ficando os fixos separados e considerados como despesas do período". Desta forma, o custeio variável tem como objetivo focar na variabilidade das despesas e gastos, direcionando os custos fixos, periódicos e repetitivos para a parte de resultados. (LEONE E LEONE, 2010). Sobre isso, o autor ainda ressalta que:

O critério do custeio variável fundamenta-se na ideia de que os custos e as despesas que devem ser inventariáveis (debitados aos produtos em processamento e acabados) serão apenas aqueles diretamente identificados com a atividade produtiva e que sejam variáveis em relação a uma medida (referência, base, volume) dessa atividade. (LEONE E LEONE, 2010, P. 320).

Sendo assim, seguindo esse fundamento, no custeio variável, os gastos absolutos variáveis devem ser proporcionais aos valores do volume do processo produtivo, o que influencia diretamente, no aumento ou redução das quantidades produzidas. (CREPALDI, 2016). 
O custeio variável tem-se tornado de muita valia e precisão para o planejamento e tomadas de decisões das empresas, isto porque, existem critérios e fatores mais lógicos, que apresentam os riscos adquiridos nos métodos com base na absorção. $\mathrm{O}$ principal argumento, é que tais métodos, não são propícios para as tomadas de decisões à curto prazo. (CREPALDI, 2016). O autor ainda sequencia os porquês:

Quadro 1: Motivos que levam ao uso do Custeio Variável segundo o autor.

A Os custos fixos por natureza operam como um todo os gastos com a - produtividade, desse modo, centraliza-se na necessidade de conhecer o montante e proporcionar um ambiente favorável para estabelecer a produção, porém, por natureza acabam não levando em consideração os custos por unidade. Tal procedimento exige a utilização de rateios, o que favorece as arbitrariedades.

B Como os rateios não estão vinculados ao custo do produto por unidade, em simulações para efeito de estoque, tornam-se menos lógicos. $E$ consequentemente, não melhora as condições para a tomada de decisão, afetando assim, informações importantes sobre a rentabilidade dos produtos, proporcionando dados inverídicos e incoerentes.

C Por fim, com esses fatores conflitantes, a distribuição dos valores dos custos

- fixos aos produtos, tendem a seguir os resultados dos rateios e a quantidade da produção, assim, os valores de custeamento de um produto, estarão propícios às variações do volume de produção até de outros produtos.

Fonte: Crepaldi, Curso Básico de Contabilidade de custos. 2016

Assim, apesar das proibições impostas pelas autoridades fiscais, o uso do custeio variável tem-se mostrado como um excelente suporte para as empresas, visto que, também tratam os custos fixos como despesas de período, de modo que, ao utilizá-lo tem-se a vantagem de alocar os custos variáveis aos produtos, o que favorece 0 resultado. (MARTINS. 2003). 


\section{MARGEM DE CONTRIBUIÇÃO}

É notório, que a aplicação do custeamento variável viabiliza um melhor controle de informações que contribuem para as decisões gerencias e valores mais lógicos que ajudam a equilibrar a equação entre a produção (por quantidade) e o lucro. Todavia, para se obter os valores coerentes da lucratividade, cujo serão capazes de suprir os valores com os gastos e despesas, se faz necessário a utilização da Margem de contribuição. (CREPALDI, 2016).

Ainda segundo o autor, para se obter tais valores, são utilizadas duas fórmulas padrão, que ajudam a calcular a margem de contribuição total e/ou a margem de contribuição unitária. A primeira, está centrada nos valores totais dos custos variáveis de um produto em questão. A segunda, foca nos valores por unidade, ou seja, quanto determinado produto custa e contribui por unidade.

Tabela 1: Fórmula da Margem de contribuição total.

$M C=R V-C V$

Fonte: Crepaldi (2016)

Para encontrar o valor da margem de contribuição $(\mathrm{MC})$, será preciso subtrair o valor das vendas totais com o valor do custo variável total (CV).

Para se estabelecer o custeamento e a lucratividade de cada produto por unidade, busca-se conhecer a margem de contribuição por unidade utilizando a fórmula abaixo.

Tabela 2: Fórmula da Margem de Contribuição Unitária

$\mathrm{MC} / \mathrm{U}=\mathrm{PV} / \mathrm{U}-\mathrm{CV} / \mathrm{U}$

Fonte: Crepaldi (2016) 
Onde se entende que, para encontrar a margem de contribuição unitária (MC/U), será preciso subtrair o preço de venda unitário (PV/U) pelo custo variável unitário (CV/U). (CREPALDI, 2016)

O uso da margem de contribuição para finalidades gerenciais e decisões, proporciona maiores precisões dos valores da lucratividade de cada produto para as empresas, isto porque, faz-se a distinção entre preço de venda, a soma dos custos totais e as despesas fixas. (MARTINS, 2003).

As principais vantagens de se estabelecer as margens de contribuição, seja total ou unitária, é que quando encontradas, ajudam nos objetivos das empresas, como por exemplo, a decidir quais produtos não tem bom rendimento. Além disso, também ajudam a decidir o momento exato para reparos e substituições; a reduzir preços para aumentar as vendas, e até mesmo, para se chegar ao ponto de equilíbrio. (CREPALDI. 2016)

$\mathrm{Na}$ seguinte tabela, tem-se um exemplo de como a Margem de contribuição, fornece informações mais consistentes sobre a lucratividade de $\mathrm{X}$ produtos.

Tabela 3: Exemplo de MC.

\begin{tabular}{|l|l|l|l|l|l|}
\hline & $\begin{array}{l}\text { Custo direto } \\
\text { variável }\end{array}$ & $\begin{array}{l}\text { Custo } \\
\text { indireto } \\
\text { variável }\end{array}$ & $\begin{array}{l}\text { Custo } \\
\text { variável } \\
\text { total }\end{array}$ & $\begin{array}{l}\text { Preço de } \\
\text { venda }\end{array}$ & $\begin{array}{l}\text { Margem de } \\
\text { contribuição }\end{array}$ \\
\hline $\begin{array}{l}\text { Produto } \\
1\end{array}$ & $\$ 700$ & $\$ 80$ & $\$ 780$ & $\$ 1.550$ & $\$ 770 /$ un. \\
\hline $\begin{array}{l}\text { Produto } \\
2\end{array}$ & $\$ 1.000$ & $\$ 100$ & $\$ 1.100$ & $\$ 2.000$ & $\$ 900 /$ un. \\
\hline $\begin{array}{l}\text { Produto } \\
3\end{array}$ & $\$ 750$ & $\$ 90$ & $\$ 840$ & $\$ 1.700$ & $\$ 860 /$ un. \\
\hline
\end{tabular}

Fonte: Martins. Contabilidade de Custos (2003). 
Assim, compreende-se que, a partir da margem de contribuição unitária, se poder chegar no valor da margem de contribuição total, e por fim, com os resultados dos cálculos, se obtém o lucro da empresa por linha de produto, por exemplo.

Feito a margem de contribuição, pode-se verificar e estabelecer o ponto de equilíbrio para as empresas.

\section{PONTOS DE EQUILÍBRIO}

O ponto de equilibro ou ponto de ruptura, é a equidade entre os custos totais com as receitas totais. O resultado do ponto de equilíbrio também dependerá do preço do produto, onde valores mais variáveis tendem a sofrer inclinações e os estáveis a alcançar a linearidade. E para se chegar a esta linearidade que o ponto de equilíbrio é utilizado. (MARTINS, 2010).

Segundo Crepaldi (2016, p. 239), "para alcançar o equilíbrio nas linhas de produção e/ou no serviço do departamento, deverá ser calculado o volume de vendas necessário para cobrir os custos". Assim, será possível entender a relação dos custos com o volume e a partir disso, estabelecer as informações desejadas sobre o lucro. Dado as informações é possível se fazer as melhores decisões quanto a: investimentos; lucratividade; cortes de produtos e mudanças dos preços conforme 0 mercado.

No gráfico abaixo, percebe-se a uniformidade, em visão global, dos custos e despesas totais com as receitas totais. 
Figura 1: Demonstração do Ponto de Equilíbrio em gráfico.

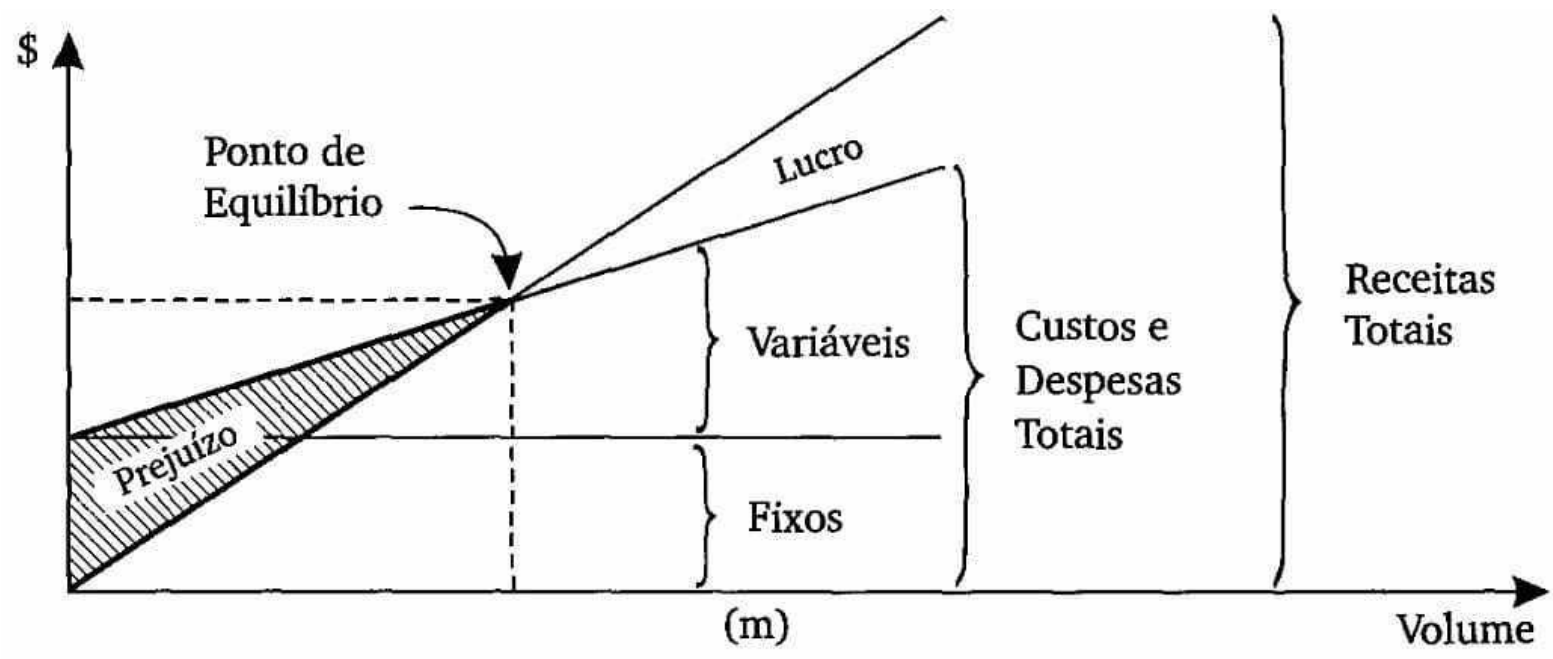

Fonte: Martins. Contabilidade de Custos. (2003).

$\mathrm{Na}$ figura acima, percebe-se que, os custos fixos permanecem estáticos independente do volume. Já os custos variáveis tendem a subir conforme o volume de vendas e quando chegam ao final da reta, representam os custos totais. No entanto, na área antes do ponto de equilíbrio, é a faixa de prejuízos, provenientes dos custos fixos e variáveis. Mas passando esta faixa, obtém-se o cruzamento da reta do custo total com a reta das receitas totais, onde não existe nem lucro e nem prejuízo, encontrando afinal, o ponto de equilíbrio. (LEONE E LEONE, 2010).

O ponto de equilíbrio também pode ser abordado de 3 maneiras distintas: pelo ponto de equilíbrio contábil (PEC); pelo ponto de equilíbrio Financeiro (PEF) e/ou ponto de equilíbrio econômico (PEE).

O PEC é o mais utilizado pela contabilidade, visto que, atua igualando os valores da receita total com o custo total. Nele, o volume de vendas cobre os custos e despesas fixas e sua principal característica é que o prejuízo e lucro é igual a 0 .

(CREPALDI, 2016)

As fórmulas do PEC para se obter, tantos valores dos volumes físicos, quanto monetários, são as seguintes: 
Figura 2: Ponto De Equilíbrio Em Unidades Físicas

$\mathrm{PE}$ (unidades físicas) $=$ Custos Fixos Totais

PVU - CUV

Onde:

PVU $=$ Preço de Venda Unitário

CUV $=$ Custo Unitário Variável

Fonte: Sebrae. Como elaborar o preço de venda. (2017)

Figura 3: Ponto De Equilíbrio Em valores monetários.

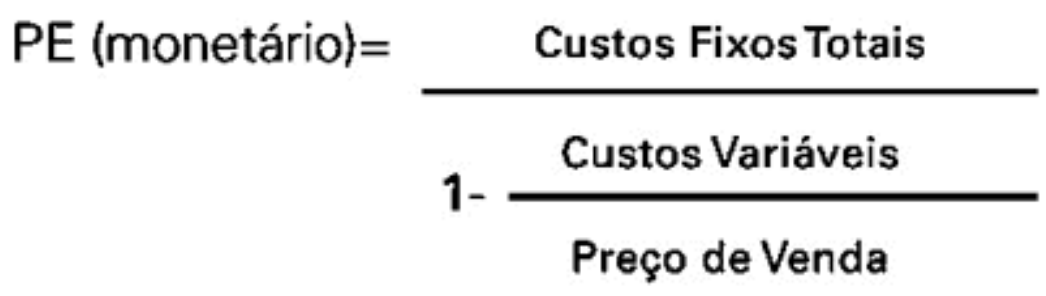

Fonte: Sebrae. Como Elaborar o Preço de Venda. (2017)

Observa-se que as 2 fórmulas se utilizam da divisão para obter os valores desejados, sendo assim, de abordagem direta e objetiva.

No PEE, centraliza-se mais nos resultados dos lucros, comparando e apresentando a rentabilidade da empresa em determinado produto ou setor, comprovando se o investimento na atividade foi lucrativo ou não. Já no PEF, o objetivo é valores significativos para suprir possíveis empréstimos e obrigações financeiras. E é através do volume de vendas que se consegue as informações desejadas. (CREPALDI,2016).

Portanto, o ponto de equilíbrio pode ser um recurso importante para se obter informações cruciais sobre o desempenho do empreendimento, pois detalha os fatores essenciais para a lucratividade e mantimento da empresa conforme o 
mercado. Principalmente, porque considera pontos como: volume de vendas; custos fixos e variáveis e o preço de venda.

\section{MARGEM DE SEGURANÇA}

A margem de segurança funciona como um indicador de risco para as empresas. Nela, é possível visualizar a quantidade adequada de vendas que a empresa precisa alcançar para não ter prejuízos. Como resultado, é apresentado os valores da produção e das vendas, que são devidamente analisados para que a empresa possa se manter na lucratividade. (CREPALDI, 2016)

Para Leone e Leone (2010, p. 352), a margem de segurança "é a diferença entre o que a empresa pode produzir e comercializar". Desta forma, posteriormente ao ponto de equilíbrio, a empresa encontra possibilidades para atingir a lucratividade.

Para calcular a margem de segurança, utiliza-se a seguinte fórmula.

Figura 4: Fórmula da MS

\section{$\%$ MS $=\quad \%$ MARGEM DE LUCRO \% MARGEM DE CONTRIBUIÇÃO}

Fonte: Crepaldi, Curso Básico de Contabilidade de Custos. (2016).

A margem de segurança da tabela acima, foi calculada desta forma para se obter o percentual, mas também pode ser expressa em valor e unidade. (CREPALDI, 2016).

\section{DEFINIÇÃO DE MICROEMPREENDEDOR INDIVIDUAL - MEI}

Segundo o Portal do Microempreendedor Individual "O microempreendedor individual - MEl é a pessoa que trabalha por sua própria conta e se legaliza como microempreendedor". Para legalizar, receber benefícios e classificar esta categoria, foi criada a lei complementar № 128 , de 2008, que considerava MEls os microempreendedores com faturamento bruto de até 60.000 mil reais. 
No entanto, a Lei Complementar no 155/2016 alterou alguns aspectos da lei complementar de 2008, principalmente o limite de faturamento bruto para MEls que atualmente é de $\mathrm{R} \$ 81.000,00$ por ano. Outros aspectos do microempreendedor individual são restrições quanto a não associação com outras empresas e um empregado com salário mínimo do piso. (PORTAL DO EMPREENDEDOR). Ainda segundo o Portal:

O MEl deverá pagar SOMENTE um valor fixo mensal de $\mathrm{R} \$ 47,85$ (comércio ou indústria) ou $R \$ 51,85$ (prestação de serviços) ou $R \$ 52,85$ (comércio e serviços). Esses valores são correspondentes ao INSS, mais $\mathrm{R} \$ 5,00$ (Município - Prestadores de Serviço) ou $\mathrm{R} \$ 1,00$ (Estado - Comércio e Indústria). O valor de INSS corresponde a $5 \%$ do salário mínimo e, portanto, pode ser reajustado. (PORTAL DO EMPREENDEDOR).

As taxas impostas para o Microempreendedor individual ainda podem variar pela influência de poderes públicos como o Estadual e o municipal, dependendo também, do tipo de atividade desempenhada ( SEBRAE, 2019)

\section{METODOLOGIA DA PESQUISA}

A presente pesquisa classifica-se quanto à sua natureza como uma pesquisa aplicada, pois utiliza-se de toda a informação disponível na geração de novos dados úteis para uma análise na prática.

Quanto à abordagem a pesquisa é caracterizada como quantitativa, pois tem a finalidade de transformar em números informações para posteriormente analisá-las. Para isso, escolheu-se um microempreendedor do ramo de Barbearia do município de Capanema, localizado no nordeste do estado do Pará. O objetivo foi levantar dados financeiros do estabelecimento, e por fim, aplicar o método de custeio variável, calculando os custos totais e as margens contributivas, com o intuito de fornecer informações importantes para a tomada de decisão do microempreendedor.

No presente trabalho foi feita uma análise mais específica na barbearia "Toc mágico" calculando sua margem de contribuição, ponto de equilíbrio, margem de segurança e por fim, sua lucratividade. Após a coleta dos dados, procedeu-se a tabulação e o 
tratamento das informações através de um sistema de informação automático, o programa Excel 2013.

\section{ANÁLISE DA BARBEARIA ESTUDADA}

Neste capítulo, apresenta-se a microempresa pesquisada, onde procedeu-se a coleta de dados, para posteriormente, fazer uma análise mais detalhada sobre os custos e as despesas existentes no negócio.

Para a presente análise utilizou-se o método do custeio variável, visto que é o método mais eficaz para tomadas de decisões à curto prazo, além de possibilitar calcular a margem de contribuição dos serviços ofertados, o ponto de equilíbrio e a margem de segurança, que são recursos essenciais para a tomada de decisão.

O objetivo foi prover o MEI de informações cruciais para o processo na tomada de decisão, colaborando de alguma forma para o sucesso e possível ampliação do empreendimento.

\section{APRESENTAÇÃO DA MICROEMPRESA E PERFIL DO MEI PARCEIRO}

A empresa parceira tem como nome fantasia Barbearia "Toc Mágico" e começou a funcionar em 05/12/1995. Têm como proprietário o senhor Nazareno Pires de Moura que trabalha há 13 anos neste setor de serviços e iniciou essa atividade como ajudante de seu pai, barbeiro há mais de 20 anos. Com o passar dos anos o sr. Nazareno desenvolveu o gosto e os conhecimentos necessários e decidiu montar seu próprio negócio. Ele possui considerável experiência na área e procurou se formalizar, e hoje, é denominado um microempreendedor individual-MEI.

Quanto ao grau de escolaridade o MEI parceiro possui apenas o ensino médio, mas tem vários cursos profissionalizantes na área de beleza masculina e está sempre se atualizando sobre as tendências deste mercado com o objetivo de se manter em desenvolvimento constante, proporcionando seu crescimento individual, e com isso, uma clientela sempre fiel. 


\section{LOCALIZAÇÃO DA MICROEMPRESA}

A Barbearia "Toc mágico" está localizada na Avenida Barão de Capanema bairroCentro, situada em ponto estratégico, local com diversas opções de lazer e grande circulação de pessoas e ainda um grande volume de comércio. $O$ bairro possui grande potencial de consumo, pois localiza-se em uma área onde as pessoas estão sempre preocupadas com a imagem pessoal e qualidade de vida. A região possui boa estrutura que fornece todos os produtos para a barbearia, além do comércio diversificado, onde situam-se muitas empresas com grande número de funcionários.

\section{CARACTERÍSTICAS DA BARBEARIA}

A barbearia está instalada em um estabelecimento alugado, em um espaço de $25 \mathrm{~m}^{2}$, equipado de bancada, armários, espelhos e materiais de serviços de barbearia. $\mathrm{O}$ horário de atendimento é de segunda a sábado das $8 \mathrm{~h}$ às $20 \mathrm{~h}$, com 2 horas para o almoço o que dá a barbearia a capacidade de atendimento de 55 horas semanais. Cada serviço tem o tempo médio de 25 minutos, que é o tempo máximo de permanência dos clientes na barbearia.

A barbearia conta com: cadeiras de barbeiro, 1 televisor, 1 bebedouro, 5 bancos para espera, 1 lavatório e uma central de ar condicionado. A barbearia "TOC MAGICO", além da qualidade nos serviços de corte de cabelo e barba, é proporcionar a seus clientes, conforto e espaço para desfrutarem de um ambiente agradável e descontraído.

\section{PROJETOS FUTUROS}

Apesar do sucesso da barbearia o proprietário tem ainda grandes ambições futuras de crescimento. O mesmo tem pretensão de ampliar seus negócios, para isso será necessário contratar mais dois funcionários e adquirir mais duas cadeiras de barbeiro. Outro projeto é sair do prédio alugado e se instalar em um local próprio. O objetivo é diminuir os custos e oferecer outros serviços aos clientes, além do corte de cabelo e barba. 
O MEI ainda estuda a viabilidade de uma barbearia temática e venda de produtos de estética masculina como: cremes, hidratantes, produtos especiais para o cuidado de barbas, cabelos e pele. Daí a importância e o interesse do proprietário em colaborar com esta pesquisa.

\section{SERVIÇOS OFERTADOS E RESPECTIVOS PREÇOS}

A tabela 4 mostra todos os serviços que são ofertados pela barbearia, e seus respectivos preços. Observou-se que os serviços possuem um valor acima do que é praticado no mercado se comparados a outras barbearias, porém é assegurado um serviço de qualidade a um custo compatível com a renda dos clientes, fator fundamental para a fidelização da clientela.

Tabela 4 - Serviços ofertados

\begin{tabular}{|l|l|}
\hline Serviços ofertados & Preços dos serviços \\
\hline Corte simples & $\mathbf{R} \$ 15,00$ \\
\hline Corte degrade & $\mathbf{R} \$ 17,00$ \\
\hline Corte só na tesoura & $\mathbf{R} \$ 20,00$ \\
\hline Barba desenhada & $\mathbf{R} \$ 15,00$ \\
\hline Barba simples & $\mathbf{R} \$ 10,00$ \\
\hline
\end{tabular}

Fonte: elaborado pelos autores (2019)

\section{CUSTOS FIXOS E VARIÁVEIS DA BARBEARIA ESTUDADA}

Os custos podem ser classificados em fixos e variáveis, diretos e indiretos e são utilizados de acordo com sua finalidade. Para esta pesquisa separamos os custos fixos e variáveis com o objetivo de facilitar o cálculo através do custeio variável.

A tabela a seguir demonstra todos os gastos mensais da Barbearia bem como as percentagens ocupadas por cada item na totalidade dos custos. 
Tabela 5- Custos Fixos e variáveis mensais.

\begin{tabular}{|c|c|c|c|c|c|}
\hline Custos Fixos & (Valor & $\begin{array}{l}\text { Custos } \\
\text { Fixos (\%) }\end{array}$ & $\begin{array}{l}\text { Custos } \\
\text { Variáveis ( }\end{array}$ & Valor & $\begin{array}{l}\text { Custos } \\
\text { Variáveis (\%) }\end{array}$ \\
\hline ALUGUEL & $\mathrm{R} \$ 900,00$ & 26,87 & GILETE & $\begin{array}{ll}R \$ & 63 \\
, 00 & \end{array}$ & 49,22 \\
\hline ENERGIA & $\mathrm{R} \$ 580,00$ & 17,32 & CREME & $\mathrm{R} \$ 9,00$ & 7,03 \\
\hline ÁGUA & $\mathrm{R} \$ 72,00$ & 2,15 & TALCO & $\mathrm{R} \$ 6,00$ & 4,69 \\
\hline CENTRAL & $\mathrm{R} \$ 15,00$ & 0,45 & PAPEL & $\begin{array}{ll}\mathrm{R} \$ & 50 \\
, 00 & \end{array}$ & 39,06 \\
\hline LIMPEZA & $\mathrm{R} \$ 160,00$ & 4,78 & & & \\
\hline DAS & $\mathrm{R} \$ 52,00$ & 1,55 & & & \\
\hline $\begin{array}{l}\text { MÃO DE } \\
\text { OBRA }\end{array}$ & $\begin{array}{l}\text { AR } \$ \\
1.500,00\end{array}$ & 44,79 & & & \\
\hline INTERNET & $\mathrm{R} \$ 70,00$ & 2,09 & & & - \\
\hline Total & $\begin{array}{l}R \$ \\
3.349,00\end{array}$ & 100,00 & Total & $\begin{array}{l}R \$ \\
128,00\end{array}$ & 100,00 \\
\hline
\end{tabular}

Fonte: Elaborado pelos autores (2019)

Evidencia-se através da tabela 7 todos os gastos mensais do objeto de estudo, tanto os custos fixos que são os gastos que não variam conforme a demanda de serviços, quanto os custos variáveis que aumentam ou diminuem de acordo com a quantidade de serviços prestados. Nota-se que os custos fixos somados se obtêm o valor de $\mathrm{R} \$$ $3.349,00$ mensais e os custos variáveis $R \$ 123,00$ mensais. Ressalta-se que os custos variáveis são muito pequenos em comparação com o total de custos fixos.

A figura 11, demonstra através dos gráficos a distribuição em valor e percentual de cada item que compõe os custos fixos da barbearia. 
Figura 5: Gráficos dos Custos fixos
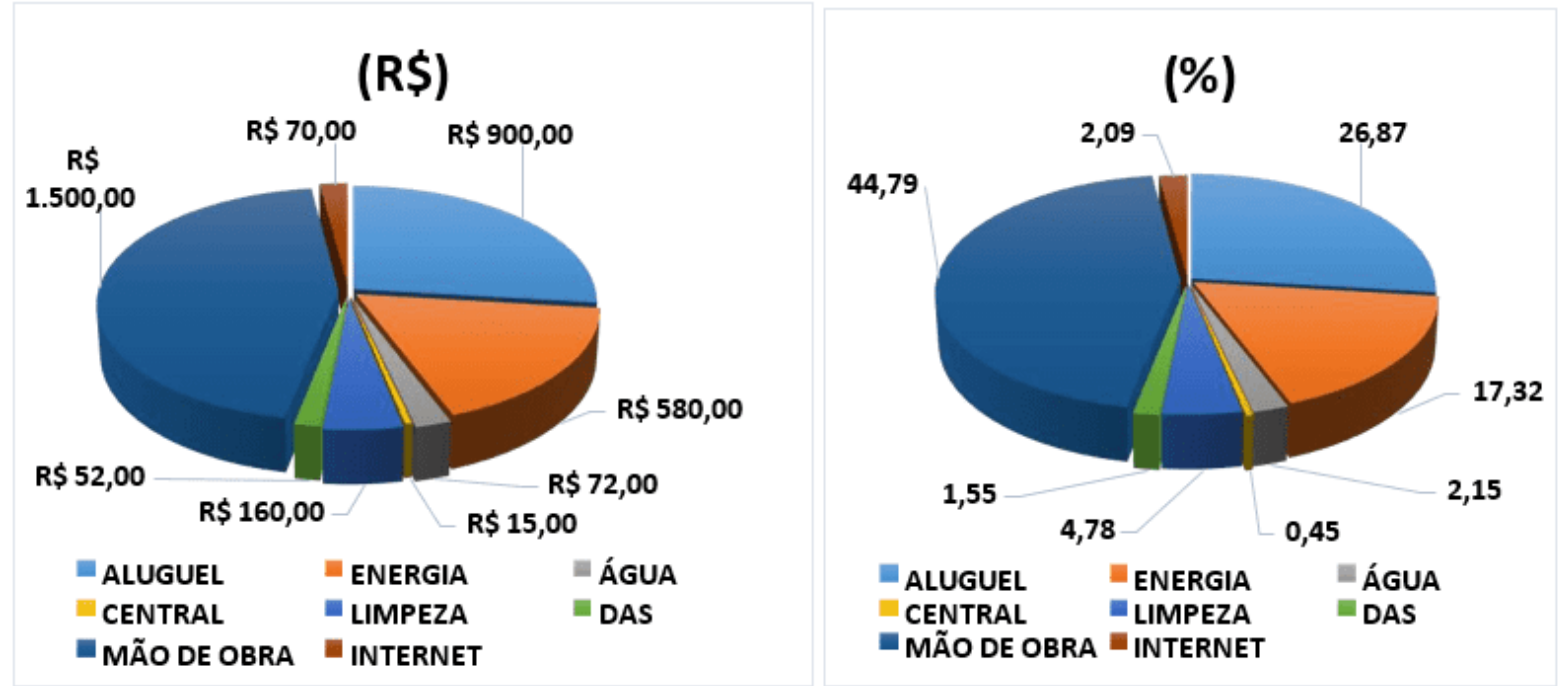

Fonte: Elaborado pelos autores (2019)

Nota-se que a parcela com maior percentual de custo fixo é referente ao prolabore do MEI, que contribui com $44,79 \%$ dos custos fixos mensais, seguido dos gastos com aluguel e energia que ocupam $26,87 \%$ e $17,32 \%$ do total dos custos fixos, respectivamente. Os demais possuem um percentual muito pequeno, que somados correspondem a apenas $10,69 \%$ do total.

Os custos variáveis mensais levantados na barbearia, possuem um valor muito pequeno se comparados aos fixos, haja vista que os serviços de barbearia consomem poucos insumos, pois o serviço é praticamente manual, constituindo um fator muito importante para a rentabilidade do negócio.

A figura 12, evidencia os valores monetários e o percentual dos custos variáveis mensais da barbearia 
Figura 6: Gráficos dos Custos variáveis

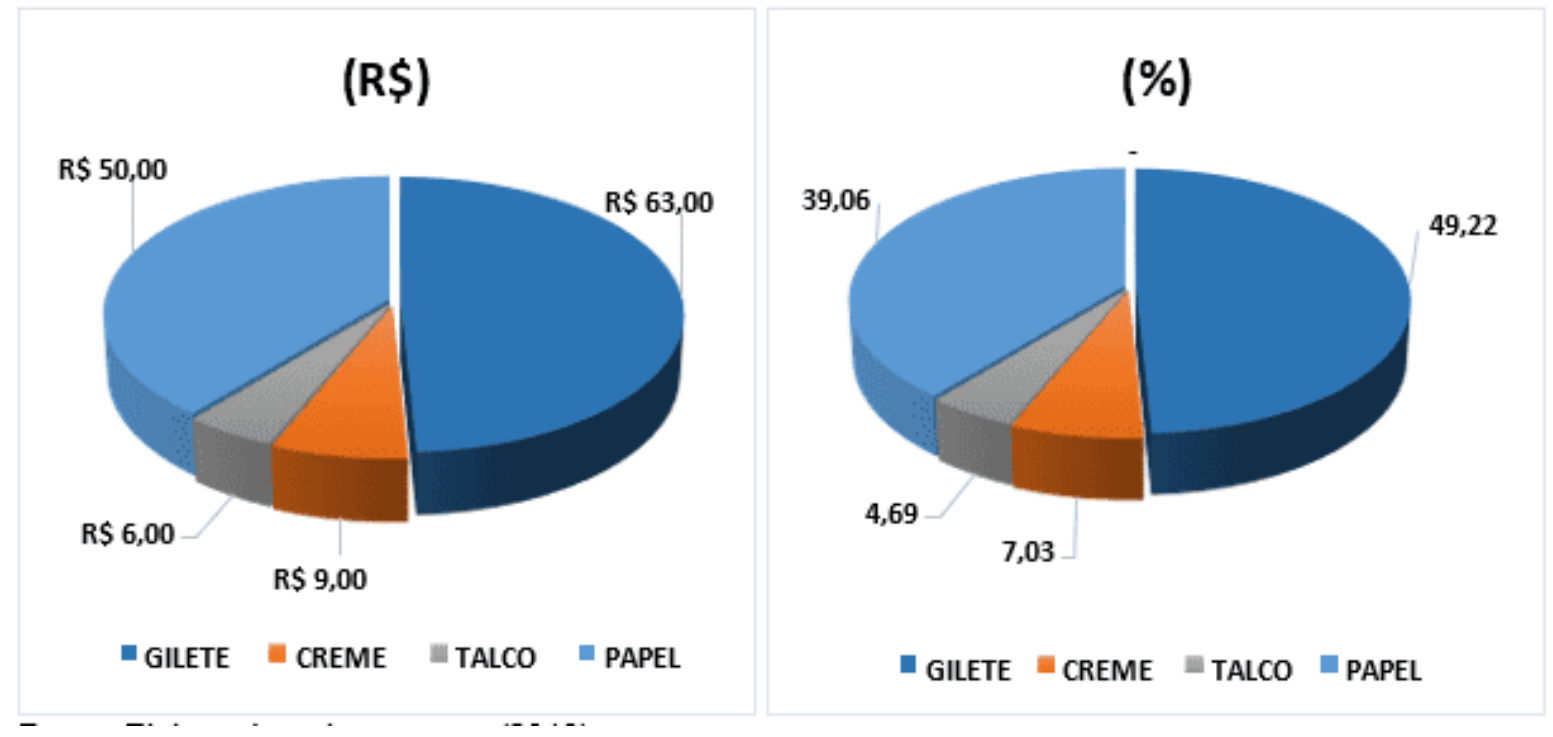

Fonte: Elaborado pelos autores (2019)

Observa-se que do total dos custos variáveis, o item gilete tem maior percentual dos custos com $49,22 \%$ do total, seguido do papel toalha que corresponde a $39,06 \%$, os itens creme e talco correspondem a 7,03\% e 4,69\% respectivamente.

\section{RECEITAS DIÁRIAS, MENSAIS E ANUAIS}

As receitas são o total do faturamento obtido com a prestação dos serviços da barbearia, que apesar de não haver um controle específico sobre suas receitas e despesas, alcançamos as informações feitas pelo proprietário de forma rústica em uma espécie de livro diário, onde são anotados o total do faturamento do dia trabalhado.

A Tabela 6 demonstra os valores das receitas tendo como base, o mês de novembro de 2018. Com essas informações foi possível elaborar uma tabela com a média mensal e anual de cada tipo de serviço. 
Tabela 6- Receitas diária, mensal e anual.

\begin{tabular}{|c|c|c|c|c|c|}
\hline Serviços & Preços & Quant. & $\begin{array}{l}\text { Receita } \\
\text { diária }\end{array}$ & $\begin{array}{l}\text { Receita } \\
\text { mensal }\end{array}$ & $\begin{array}{l}\text { Receita } \\
\text { anual }\end{array}$ \\
\hline Corte simples & $\begin{array}{l}R \$ \\
15,00\end{array}$ & 6 & $\mathrm{R} \$ 90,00$ & $\mathrm{R} \$ 2.340,00$ & $\begin{array}{l}\mathrm{R} \$ \\
28.080,00\end{array}$ \\
\hline Corte degrade & $\begin{array}{l}R \$ \\
17,00\end{array}$ & 4 & $\mathrm{R} \$ 68,00$ & $\mathrm{R} \$ 1.768,00$ & $\begin{array}{l}\mathrm{R} \$ \\
21.216,00\end{array}$ \\
\hline Só na tesoura & $\begin{array}{l}R \$ \\
20,00\end{array}$ & 1 & $\mathrm{R} \$ 20,00$ & $\mathrm{R} \$ 520,00$ & $\mathrm{R} \$ 6.240,00$ \\
\hline $\begin{array}{l}\text { Barba } \\
\text { desenhada }\end{array}$ & $\begin{array}{l}R \$ \\
15,00\end{array}$ & 2 & $\mathrm{R} \$ 30,00$ & $\mathrm{R} \$ 780,00$ & $\mathrm{R} \$ 9.360,00$ \\
\hline Barba simples & $\begin{array}{l}R \$ \\
10,00\end{array}$ & 5 & $\mathrm{R} \$ 50,00$ & $\mathrm{R} \$ 1.300,00$ & $\begin{array}{l}R \$ \\
15.600,00\end{array}$ \\
\hline Total & & 18 & $\mathrm{R} \$ 258,00$ & $\mathrm{R} \$ 6.708,00$ & $\begin{array}{l}\mathrm{R} \$ \\
80.496,00\end{array}$ \\
\hline
\end{tabular}

Fonte: Elaborado pelos autores (2018)

Observa-se nesta tabela que o MEI possui um faturamento diário no valor de $\mathrm{R} \$$ 258,00 , um faturamento mensal no valor de $R \$ 6.708,00$ e o faturamento anual de $\mathrm{R} \$ 80.496,00$, observe que o valor anual não ultrapassa o valor máximo de $\mathrm{R} \$ 81.000,00$, portanto o proprietário pode ser enquadrado como microempreendedor individual.

\section{ANÁLISE DA MARGEM DE CONTRIBUIÇÃO}

Uma das vantagens de se trabalhar com o custeio variável é que, proporciona maiores precisões dos valores da lucratividade de cada produto para as empresas, porque consegue-se distinguir o preço de venda, a soma dos custos totais e as despesas fixas. (MARTINS, 2003). 
A margem de contribuição é uma ferramenta utilizada por este método e permite ao usuário, verificar o quanto cada serviço, contribui para a liquidação dos custos fixos, e assim, estabelecer o preço ideal para que a empresa esteja concorrendo no mercado competitivo. Estando ciente dos valores das receitas e despesas variáveis unitárias é possível identificar qual o serviço mais rentável para a empresa e dessa forma auxiliar o MEI na tomada de decisão, pois permite saber se vale a pena prosseguir com a prestação de determinado serviço.

A tabela 7 evidencia os valores da margem de contribuição unitária e o lucro de cada serviço da barbearia.

Tabela 7- margem de contribuição unitária.

\begin{tabular}{|c|c|c|c|}
\hline SERVIÇOS & $\begin{array}{l}\text { PREÇO DE } \\
\text { VENDA }\end{array}$ & $\begin{array}{l}\text { CUSTO VARIÁVEL } \\
\text { UN. }\end{array}$ & $\begin{array}{l}\text { M.CONTRIBUIÇÃO } \\
\text { UN. }\end{array}$ \\
\hline CORTE SIMPLES & $R \$ 15,00$ & $\mathrm{R} \$ 0,26$ & $\mathrm{R} \$ 14,74$ \\
\hline CORTE DEGRADE & $\mathrm{R} \$ 17,00$ & $\mathrm{R} \$ 0,26$ & $\mathrm{R} \$ 16,74$ \\
\hline $\begin{array}{l}\text { CORTE } \\
\text { TESOURA }\end{array}$ & $\mathrm{R} \$ 20,00$ & $\mathrm{R} \$ 0,26$ & $\mathrm{R} \$ 19,74$ \\
\hline $\begin{array}{l}\text { BARBA } \\
\text { DESENHADA }\end{array}$ & $\mathrm{R} \$ 15,00$ & $\mathrm{R} \$ 0,26$ & $\mathrm{R} \$ 14,74$ \\
\hline BARBA SIMPLES & $\mathrm{R} \$ 10,00$ & $\mathrm{R} \$ 0,26$ & $\mathrm{R} \$ 9,74$ \\
\hline
\end{tabular}

Fonte: Elaborado pelos autores (2019)

Com base nestas informações é possível conhecer o quanto cada serviço prestado consegue obter de lucro para a empresa. O que se observa na tabela acima é que todos os serviços possuem uma boa margem de contribuição, pois os custos variáveis não variam, dando destaque para o corte só na tesoura que é o serviço mais rentável da barbearia deixando um lucro de $R \$ 19,74$ por cada corte e a barba simples $R \$ 9,74$ como o serviço menos rentável, mas que ainda possui uma margem de contribuição bem significativa. 
Na figura 13 evidencia os valores percentuais da margem de contribuição unitária.

Figura 7: percentual de margem de contribuição por serviço

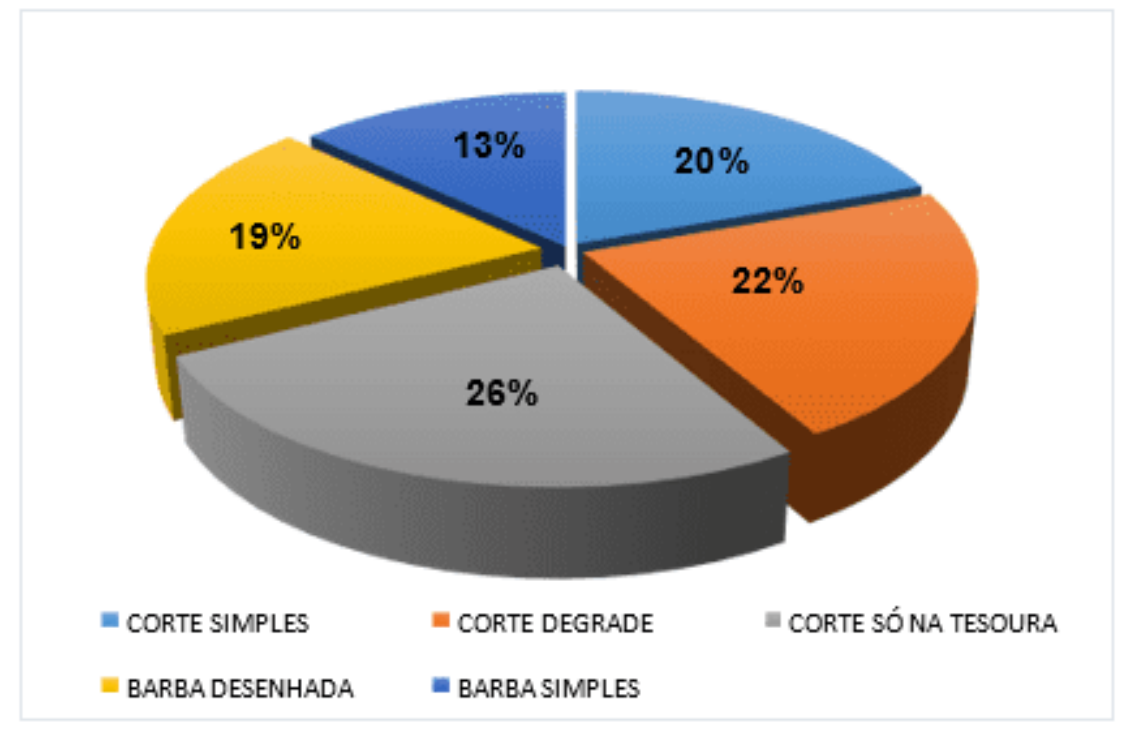

Fonte: Eborado pelos autores (2019)

Através da figura acima temos uma boa percepção sobre a representatividade de cada serviço e o quanto contribui para a geração de receita do empreendimento estudado. Observa-se que todos os serviços contribuem com uma parcela significativa para o faturamento da empresa, com destaque para o corte só na tesoura que corresponde a $26 \%$ seguida do corte degrade com $22 \%$, o corte simples e a barba desenhada com $20 \%$ e 19\% respectivamente. A barba simples é o serviço que possui menor participação com apenas $13 \%$ do faturamento da receita.

\section{MARGEM DE CONTRIBUIÇÃO TOTAL E LUCRATIVIDADE}

A margem de contribuição total permite aos gestores compreender melhor sobre a rentabilidade total do empreendimento. Se a empresa está ou não dando o lucro desejado. Através destas informações, foi possível elaborar uma tabela da margem de contribuição total e o percentual de lucratividade do negócio, como mostra a tabela 8. 
Tabela 8- Margem de Contribuição Total e Lucratividade

\begin{tabular}{|c|c|c|}
\hline$(+)$ & Receita Bruta & $\mathrm{R} \$ 6.708,00$ \\
\hline$(-)$ & Deduções de Vendas (Impostos) & $0 \%$ \\
\hline \multirow[t]{2}{*}{$(=)$} & Receita Líquida & $\mathrm{R} \$ 6.708,00$ \\
\hline & Custos variáveis & \\
\hline$(-)$ & Matéria-Prima & $\mathrm{R} \$ 120,00$ \\
\hline$(-)$ & Mão-de-Obra Direta & $\mathrm{R} \$ 00,00$ \\
\hline$(=)$ & Margem de Contribuição & $\mathrm{R} \$ 6.588,00$ \\
\hline \multirow{2}{*}{$(=)$} & Margem de Contribuição (\%) & $98,21 \%$ \\
\hline & Custos fixos & \\
\hline$(-)$ & Aluguel & $\mathrm{R} \$ 900,00$ \\
\hline$(-)$ & Pró Labore e Salários & $\mathrm{R} \$ 1.500,00$ \\
\hline$(-)$ & Encargos e Benefícios & $\mathrm{R} \$ 52,00$ \\
\hline$(-)$ & Telefone e Internet & $\mathrm{R} \$ 70,00$ \\
\hline$(-)$ & Luz, Água, Gás etc. & $\mathrm{R} \$ 652,00$ \\
\hline$(-)$ & Outros Custos Fixos & $\mathrm{R} \$ 175,00$ \\
\hline \multirow[t]{2}{*}{$(=)$} & Custos Fixos & $\mathrm{R} \$ 3.239,00$ \\
\hline & Lucratividade & \\
\hline \multirow[t]{2}{*}{$(=)$} & Lucro Bruto & $\mathrm{R} \$ 3.239,00$ \\
\hline & Imposto sobre o Lucro (IRPJ e CSLL) & $0,00 \%$ \\
\hline$(=)$ & Lucro Líquido & $\mathrm{R} \$ 3.239,00$ \\
\hline$(=)$ & Lucratividade & $48,28 \%$ \\
\hline
\end{tabular}

Fonte: Elaborado pelos autores (2018)

Concluiu-se com os dados da tabela acima, que a microempresa apresenta um percentual de margem de contribuição total de $75,85 \%$ e após a quitação de todos os custos fixos um lucro líquido de $R \$ 1.739,00$ que equivale a uma lucratividade mensal de $25,90 \%$ da receita líquida de serviços. Com isso, observa-se que a empresa possui uma excelente margem de contribuição e uma satisfatória lucratividade para o sucesso do empreendimento. 


\section{ANÁLISE DO PONTO DE EQUILÍBRIO CONTÁBIL}

O ponto de equilíbrio contábil é a quantidade mínima de serviço necessário para a empresa acumular receita e, assim, liquidar todos os custos. É o ponto em que o lucro da empresa é zero, ou seja, o total da receita iguala-se a todos os custos e despesas, é também conhecido como ponto crítico. Para este cálculo utilizamos a seguinte fórmula:

$\mathrm{PEC}=($ Custos fixos + despesas fixas) / margem de contribuição unitária

Tabela 9- Ponto de equilíbrio contábil de cada tipo de serviço.

\begin{tabular}{|c|c|c|c|c|c|c|}
\hline \multicolumn{7}{|c|}{ Ponto de equilíbrio por serviço } \\
\hline SERVIÇOS & & M.C & & C.F & P.E.C & Total do faturamento \\
\hline Corte simples & $\mathrm{R} \$$ & 14,74 & $\mathrm{R} \$$ & $3.349,00$ & 227 & $\mathrm{R} \$ 3.408,07$ \\
\hline Corte em Degrade & $\mathrm{R} \$$ & 16,74 & $\mathrm{R} \$$ & $3.349,00$ & 200 & $3.401,02$ \\
\hline Corte só na tesoura & $\mathrm{R} \$$ & 19,74 & $\mathrm{R} \$$ & $3.349,00$ & 170 & $3.393,11$ \\
\hline Barba desenhada & $\mathrm{R} \$$ & 14,74 & $\mathrm{R} \$$ & $3.349,00$ & 227 & $3.408,07$ \\
\hline Barba simples & $\mathrm{R} \$$ & 9,74 & $\mathrm{R} \$$ & $3.349,00$ & 344 & $3.438,40$ \\
\hline
\end{tabular}

Fonte: elaborado pelos autores (2019)

$\mathrm{Na}$ tabela acima tem-se o ponto de equilíbrio de cada serviço, que é a quantidade necessária que a empresa precisa vender para não ter prejuízo, ou seja, todo o valor arrecadado acima desse nível é lucro e abaixo desse valor significa prejuízo. Nota-se na tabela acima, que o valor do faturamento mensal praticamente iguala-se ao valor dos custos fixos totais.

\section{ANÁLISE DA MARGEM DE SEGURANÇA OPERACIONAL}

A margem de segurança operacional permite ao empresário verificar a capacidade de geração de lucro da microempresa, é o quanto a empresa consegue vender acima do ponto de equilíbrio. A tabela abaixo mostra a quantidade de serviços que a barbearia consegue realizar acima do ponto crítico. 
Tabela 10- Representação quantitativa e percentual do MSO

\begin{tabular}{|l|l|l|l|l|}
\hline SERVIÇOS & QUANT. VENDIDA & P.E.C & M.S.O & $\%$ \\
\hline CORTE SIMPLES & 448 & 227 & 221 & 49,3 \\
\hline DEGRADE & 448 & 200 & 248 & 55,4 \\
\hline SÓ NA TESOURA & 448 & 170 & 278 & 62,1 \\
\hline BARBA DESENHADA & 448 & 227 & 221 & 49,3 \\
\hline BARBA SIMPLES & 448 & 344 & 104 & 23,2 \\
\hline
\end{tabular}

Fonte: elaborado pelos autores (2019)

Percebe-se através da tabela acima que a barbearia opera com todos os serviços acima de $48 \%$ em média de MSO, significa dizer que, mesmo que as quantidades de serviços reduzam pela metade a microempresa ainda será capaz de liquidar todos os seus custos fixos.

A figura abaixo evidencia o percentual de margem de segurança que cada serviço oferece à barbearia.

Figura 8: percentual de margem de segurança por tipo de serviço

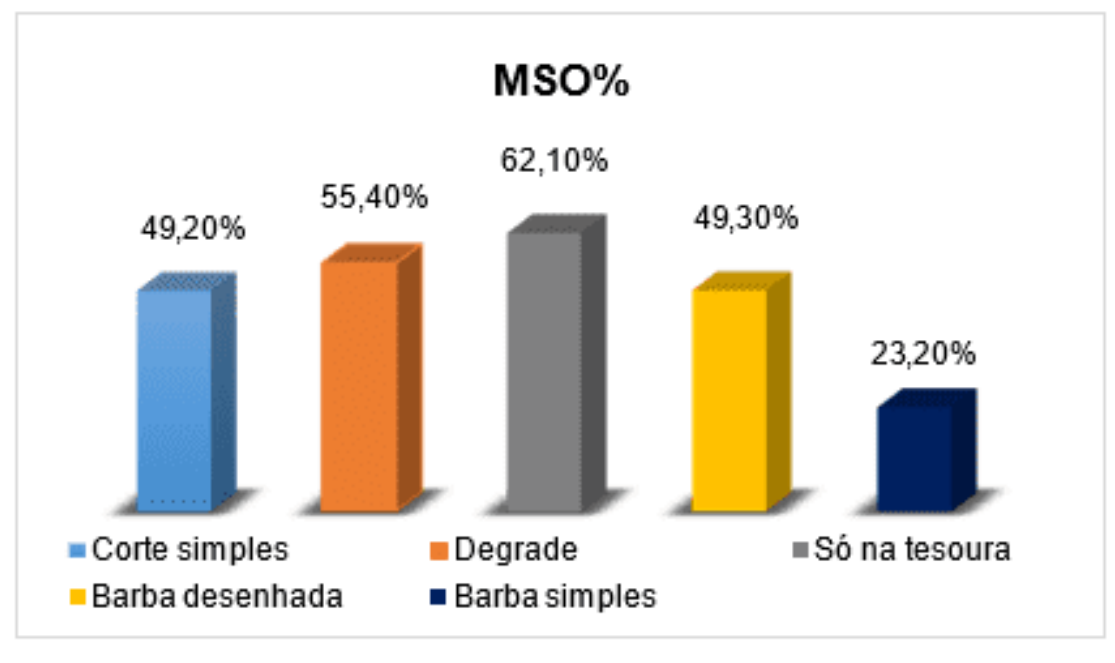

Fonte: Elaborado pelos autores (2019) 
A figura acima mostra que o empreendedor apresenta uma maior margem de segurança no corte só na tesoura que equivale a $62,10 \%$ e uma menor margem de segurança no serviço de barba simples que equivale a $23,20 \%$. Constatando-se, portanto, que a barbearia possui grande capacidade de geração de lucro em todos os seus serviços proporcionando maior segurança para a microempresa e assegurando que a mesma não incorrerá em prejuízos.

\section{CONSIDERAÇÕES FINAIS}

Através deste trabalho ficou evidenciado que apesar do período de crise econômica que o País tem enfrentado, esse setor de serviço vem crescendo exponencialmente no município estudado, seguindo a tendência mundial do homem moderno que está cada vez mais preocupado com sua imagem pessoal e saúde.

Conclui-se que a microempresa se encontra atualmente em uma situação bem confortável financeiramente, com uma boa margem de contribuição dos seus serviços e a margem de segurança operando bem acima do ponto de equilíbrio, o que possibilitou constatar que a microempresa estudada, além de possuir boa lucratividade, consegue honrar com todos os seus gastos, logo possui uma margem de lucro estável, que poderá servir para futuros investimentos.

Para futuras pesquisas, sugere-se a elaboração de um plano de negócios e a partir da aplicação desse recurso, por exemplo, viabilizar uma barbearia temática. Visto que, ao analisar os pontos positivos e negativos do mercado capanemense, perceberá se este investimento adicional é viável e como poderá contribuir para o crescimento da microempresa, dando maior segurança para futuros investimentos ao MEl estudado.

\section{REFERÊNCIAS}

CREPALDI, Silvio A. Curso básico de contabilidade de custos- 5. Ed. - São Paulo: Atlas, 2016.

GIL, Antônio Carlos, 1946-Como elaborar projetos de pesquisa/Antônio Carlos Gil. 4. ed. - São Paulo, Atlas, 2002 Bibliografia. 
LEONE, George Sebastião Guerra. Curso de contabilidade de custos: contem critério do custeio ABC. São Paulo: Atlas, 1997.

LEONE, George S. Guerra; LEONE, Rodrigo. J. Guerra. Curso de contabilidade de Custos. - 4.ed.-São Paulo: Atlas, 2010.

MARTINS, Eliseu. Contabilidade de custos - 9. ed. - São Paulo: Atlas, 2003.

PROENÇA, F. Rogerio; SANTOS, Joenice Leandro D. dos. Custos e formação de preço. Londrina: Editora e Distribuidora Educacional S.A., 2014.

PORTAL DO EMPREENDEDOR. Vantagens em ser MEI. Disponível em: $<$ https://www.oportaldoempreendedor.com/registro?ref=google $<$ acesso $\geq$ Acessado em 20-01-19.

PORTAL DO MICROEMPREENDEDOR INDIVIDUAL. Disponível em: <https://www.portalmei.org/ > Acessado em 20-01-19.

SEBRAE. Brasileiros irão liderar as vendas no mercado de beleza. 2018 Disponível em: <http://blog.sebrae-sc.com.br/brasileiros-mercado-de-beleza-masculina> Acesso em 20-01-19

. Panorama Sebrae. Núcleo de inteligência institucional da Unidade de gestão estratégica do Sebrae. 2018

VIEIRA, Eusélia Paveglio. Custos e formação do preço de venda. - ljuí : Ed. Unijuí, 2008. - 106 p.; il. - (Coleção educação a distância. Série livro-texto).

Enviado: Setembro, 2019.

Aprovado: Outubro, 2019. 